\title{
Contribuiç̃oes e limitações dos métodos de alfabetização de crianças
}

\author{
CONTRIBUTIONS AND LIMITATIONS OF THE TEACHING METHODS \\ IN CHILDREN'S LITERACY
}

\section{Greici Quéli MACHADO * Rosangela GABRIEL **}

Resumo: Para que a aprendizagem da leitura e da escrita transcorra de forma eficiente, a análise dos métodos de alfabetização é de fundamental importância. Para assinalar quais as melhores estratégias a serem usadas na aprendizagem da leitura e da escrita de crianças, de forma a oferecer as condições para o aprendiz iniciar-se no mundo letrado, é necessário analisar a alfabetização sob três pontos de vista, conforme descrito por Soares $(2003,2007)$. O primeiro diz respeito à questão técnica da língua, ou seja, ao ato de decodificação e codificação, à relação grafema-fonema / fonema-grafema. O segundo atém-se à questão do significado, da compreensão leitora. E o terceiro considera a alfabetização um processo social, ou seja, a aprendizagem da língua escrita possui funções conforme o contexto social em que está inserida. Este estudo foi concebido com o intuito de discutir os argumentos favoráveis e contrários aos métodos fônico e global. Além da comparação de argumentos teóricos, foram realizadas entrevistas com professores alfabetizadores acerca da metodologia usada na alfabetização. Os resultados sugerem que tanto o método fônico quanto o global apresentam argumentos legítimos no que tange à alfabetização de crianças. Seguindo esse raciocínio, é sensata a busca pelo equilíbrio no uso dos dois métodos de alfabetização. Respeitar o caminho dos alunos no desenvolvimento de suas hipóteses sobre a escrita, possibilitar o trabalho com textos, explorar as relações entre fonemas e grafemas, desenvolver a consciência fonológica, valorizar as

* Mestre em Letras, área de concentração Leitura e Cognição, pela Universidade de Santa Cruz do Sul (UNISC), RS. Contato: greiciqm@yahoo.com.br.

** Doutora em Letras pela PUCRS (2001), tendo realizado doutorado-sanduíche no Departamento de Psicologia Experimental da Universidade de Oxford / Inglaterra (1999-2000). Professora da Universidade de Santa Cruz do Sul (UNISC), RS. Contato: rgabriel@unisc.br. 
descobertas dos aprendizes, apresentar a leitura como uma atividade ao mesmo tempo prazerosa e significativa na dinâmica social, são objetivos compatíveis e complementares no processo de alfabetização e letramento de jovens leitores. Palavras-chave: Alfabetização de crianças; Método global; Método fônico.

\begin{abstract}
In order to improve reading and writing learning, the analysis of the teaching methods is of fundamental importance. According to Soares (2003, 2007), to highlight which are the best strategies to be used on teaching reading and writing to children, in order to offer all the conditions for the learner to be initiated in the literate world, it is necessary to analyze the literacy under three points of view. The first one concerns to the technical subject of the language, that is, the decoding and coding action, the conversion grapheme-phoneme/ phoneme-grapheme. The second one focus attention on meaning, on reading comprehension, while the third point considers literacy a social process, that is, the learning of the written language possesses functions and objectives according to the social context in which it is inserted. Starting from that, this study was conceived with the intention of discussing the favorable and contrary arguments to the phonics and global methods in children's literacy, with the aim of investigating which is the best way of teaching reading and writing. Besides the comparison of theoretical issues, interviews with first year's school teachers about the teaching methods they adopt were conducted. The results suggest that both methods, the global and the phonics, present legitimate arguments concerning reading and writing teaching. Following that reasoning, it is wise to search for a balance in using the best of both methods. In order to reach literacy with quality, it is necessary to respect the students' trajectory in the development of their hypotheses, to make possible the work with texts, to rescue the importance of teaching the alphabet and the relationships between sounds and letters, to respect the moments of discoveries of the learners, to present reading at the same time as a pleasure and as a fundamental tool in the social dynamics.
\end{abstract} Key-words: Children's Literacy; Whole language approach; Phonics approach.

\title{
Introdução: alfabetização e letramento em foco
}

A leitura representa uma ferramenta primordial para a formação do sujeito, no aspecto social e cognitivo, vis to que é através dela que se chega a uma fatia substancial do conhecimento construído pela espécie. A partir dos avanços das Ciências Cognitivas, a leitura passou a ocupar um espaço privilegiado nas pesquisas científicas e muitos pesquisadores dedicam-se a desvendar os seus mistérios. 
Conforme informações fornecidas pelos órgãos que avaliam a educação, vê-se que o Brasil atravessa uma fase difícil, com resultados alarmantes. Dados estatísticos fornecidos pelo INEP mostram que a percentagem de reprovação na primeira série do Ensino Fundamental aumentou de 15,1\% no ano de 2000 para 16,1\% em 2005 evidenciando, assim, que o sistema educacional vigente não está gerando bons resultados. De acordo com a avaliação do PISA, de 2006, o Brasil é um dos piores países na avaliação de proficiência em leitura, classificando-se em $49^{\circ}$ lugar dentre os cinquenta e seis países participantes. No Brasil apenas 1,1\% dos estudantes atingiram o nível mais alto de proficiência em leitura, e 44,5\% alcançaram apenas o nível 2 em leitura, o que significa que "enfrentam dificuldades quando precisam de material de leitura para alcançar objetivos de aprendizado em qualquer área" (INEP). Os dados do SAEB (Sistema de Avaliação da Educação Básica), de 2005, mostram que nos últimos dez anos a educação no Brasil piorou, ou seja, em todos os dados comparativos, o desempenho dos alunos na avaliação de 2005 é inferior ao de 1995. Os alunos de $4^{a}$ série do Ensino Fundamental em 1995 receberam a média em proficiência em Língua Portuguesa de 188 pontos e, em 2005, essa média caiu para 172 pontos. Evidencia-se, por meio desses dados, que grande parte dos alunos brasileiros chega à $4^{\mathrm{a}}$ série do ensino fundamental sem ter desenvolvido as competências em leitura exigidas para esse nível.

Nesse sentido, para que a aprendizagem da leitura transcorra de forma eficiente, a análise dos métodos de ensino é de fundamental importância, pois, através da comparação entre os processos cognitivos e os métodos de alfabetização, será possível assinalar quais são as melhores estratégias a serem usadas na aprendizagem da leitura e da escrita de crianças, de forma a oferecer as condições necessárias para o aprendiz iniciar-se no mundo letrado. Soares (2007, p. 24) salienta que, "a questão dos métodos, que tanto tem polarizado as reflexões sobre alfabetização, será insolúvel enquanto não se aprofundar a caracterização de diversas facetas do processo e não se buscar uma articulação dessas diversas facetas nos métodos e procedimentos de ensinar a ler e a escrever".

A alfabetização precisa ser observada sob três pontos de vista, os quais são tomados como referência neste artigo. Os dois primeiros 
consideram a alfabetização como um processo individual: o primeiro diz respeito à questão técnica da língua, ou seja, o ato de decodificação e codificação, a representação grafema-fonema / fonema-grafema. Aprender a ler e a escrever envolve relacionar sons com letras para codificar ou para decodificar; envolve, também, aprender a segurar um lápis, que se escreve de cima para baixo e da esquerda para a direita, enfim, envolve uma série de aspectos técnicos indispensáveis. O segundo ponto de vista atém-se à questão do significado, da compreensão leitora. Já o terceiro considera a alfabetização como um processo social, ou seja, o aprendiz precisa tomar conhecimento das funções e fins que a escrita assume conforme o contexto social em que está inserida, para assim tornar-se um usuário ativo dessa modalidade da língua (SOARES, 2003; 2007).

Vinculado ao conceito de alfabetização, o letramento é considerado como "o resultado da ação de ensinar ou de aprender a ler e a escrever, bem como o resultado da ação de usar essas habilidades em práticas sociais" (BATISTA et al., 2007), isto é, o processo de inserção e participação na cultura escrita. Pesquisadores envolvidos com a educação, como Soares (2000, 2002), Kleiman (2002), Marcuschi e Xavier (2005), entre outros, comprometidos em definir e discutir o termo, explicam que letramento é o uso da leitura e da escrita como práticas sociais, articulando-as conforme as situações, como fios condutores para a apropriação da linguagem e do conhecimento.

Este artigo ${ }^{2}$ tenta contribuir com os estudos acerca da aprendizagem da leitura e da escrita através da comparação entre os argumentos e contra-argumentos fornecidos pelos métodos de alfabetização fônico e global. Por meio do levantamento e discussão dos argumentos apresentados pelos defensores de ambos os métodos, tentamos responder à questão: Qual a metodologia mais eficiente na alfabetização de crianças?

\footnotetext{
${ }^{2}$ Este artigo é fruto das pesquisas desenvolvidas pela primeira autora ao longo de seu curso de Mestrado na Universidade de Santa Cruz do Sul-RS, sob a orientação da segunda autora. O conteúdo deste texto foi apresentado inicialmente como comunicação oral durante o "I Congresso Internacional de Leitura e Literatura Infantil e Juvenil”, promovido pela PUCRS, em junho de 2008.
} 


\section{Métodos de ensino da leitura: pertinência da questão}

A busca por um método eficaz para o ensino da leitura é uma questão extremamente pertinente, pois, como afirma Scliar-Cabral (2003, p.20), "é nos primeiros anos de escola que se decide fundamentalmente quem será um bom leitor ou redator".

Adams et al. (2003) sugerem que os métodos de alfabetização devem basear-se em conhecimentos científicos acerca da escolha das unidades de ensino (grafema / fonema, sílabas, palavras, sentenças, textos), bem como aqueles relativos às regras elementares para auxiliar o aluno a decifrar o código alfabético, as estruturas linguísticas e as regras mais complexas com as quais ele terá de lidar ao ler, ou ao ouvir textos lidos em classe pelo professor, além de entender como se desenvolvem os padrões ortográficos e como a decodificação contribui para o desenvolvimento desses padrões.

Grossi (1995, p. 113) ressalta que "uma nova abordagem do aprendizado deveria estabelecer uma correspondência entre as descobertas no campo da psicologia cognitiva, no que tange à alfabetização, e o desempenho do professor em sala de aula". Ou seja, um método de alfabetização deve sempre atualizar-se quanto às novas descobertas da psicologia cognitiva e, ao mesmo tempo, ambientar os professores alfabetizadores a fim de que possam usufruir dessas novas descobertas.

Kato (1995, p. 6), igualmente, já abordara essa questão ao afirmar que "qualquer método para ser eficaz deve ter a ele subjacentes hipóteses claras sobre a natureza da aprendizagem desse objeto".

Cumpre observar que os autores citados nos parágrafos anteriores, apesar de defenderem métodos de alfabetização distintos, concordam que a escolha do método deva ser pautada pelos conhecimentos científicos disponíveis nas áreas da linguística, psicologia, educação, etc. Na sequência, buscamos confrontar os argumentos trazidos pelos métodos fônico e global à luz de nossos conhecimentos atuais.

\section{O confronto: método fônico versus método global}

Conforme Morais (1996, p. 262), o método fônico nasceu na 
Alemanha no século XVI com o propósito de ensinar as correspondências entre sons e letras. Esse método "nasceu de uma constatação: a criança sente dificuldades em passar da associação entre o nome das letras para a fusão dos 'sons' das letras a fim de obter a pronúncia das palavras". As pesquisas sobre o método fônico investigam a importância do domínio do sistema alfabético por meio de uma metodologia voltada para a consciência fonológica, a fim de que, durante a aquisição da linguagem escrita, a criança internalize padrões regulares entre som e letra.

O método fônico pretende desenvolver a consciência fonológica e está voltado para a capacidade da criança em refletir sobre as unidades sonoras constitutivas das palavras (correspondência grafema / fonema). Durante a aquisição da linguagem escrita, predomina a intenção de que a criança internalize padrões regulares entre som e letra (MC GUINNESS, 2006).

De acordo com esse pensamento, a compreensão da leitura só será atingida depois que a criança dominar a correspondência grafema/ fonema, porque, nessa visão, a escrita serve para representar graficamente a fala. Assim, esse método atribui grande importância à decodificação, pois, segundo ele, a aprendizagem da leitura e da escrita se constrói introduzindo os elementos de forma gradual, primeiro unidades mais simples - letras e sílabas - para depois as mais complexas - palavras, frases e textos.

Já os defensores do método global propõem uma alfabetização contextualizada através da transposição das práticas sociais de leitura para a sala de aula em situações-problema. Grossi (1989, p. 31-32) afirma que "o conhecimento se dá através da interação dos estímulos do meio ambiente com o sujeito que aprende [...] o centro do processo de aprendizagem é o próprio aluno, como sujeito que aprende e que constrói o seu saber".

O método global prioriza as atividades comunicativas por meio do uso da linguagem. Nessa abordagem, a aprendizagem é tomada de forma ampla e engloba diversos fatores como a interdisciplinaridade, o desenvolvimento corporal e as dimensões sociais e afetivas. Para o método global, a leitura é um processo de identificação global das palavras, em que os elementos são introduzidos a partir de estruturas complexas, deslocando-se em seguida para as simples - textos, frases, 
palavras, sílabas e letras. Dessa forma, a aprendizagem da leitura e da escrita requer a memorização de palavras inteiras para, posteriormente, o leitor descobrir as unidades linguísticas mínimas (MORAIS, 1996).

Nessa perspectiva, ressaltam-se os estudos de Emília Ferreiro, baseados nos trabalhos de Jean Piaget. O objetivo fundamental desses estudos, segundo Ferreiro (1995, p. 23), é o "entendimento da evolução dos sistemas de ideias construídos pelas crianças sobre a natureza do objeto social que o sistema de escrita é". Ferreiro e Teberosky (1985) investigam a natureza da relação entre o real e sua representação e, em resposta, afirmam que as crianças reinventam a escrita, construindo hipóteses sobre ela. Seguindo a evolução das hipóteses infantis, as autoras dividem o processo da aprendizagem da leitura e da escrita em níveis distintos: pré-silábico I e II, silábico, silábico-alfabético, alfabético e ortográfico.

O método global é fortemente associado à ludicidade, ao prazer, à investigação do significado das palavras, ao trabalho direcionado ao contexto em que o aluno está inserido e, principalmente, aos níveis psicogenéticos da escrita, que funcionam como um termômetro e permitem aos professores identificar a evolução da aprendizagem dos seus alunos e, a partir daí, reelaborar a sua prática.

Defensores do método fônico, Morais e colaboradores (2004) afirmam que os programas que exercitam a consciência fonológica permitem progressos mais significativos em leitura e escrita do que aqueles que não o enfatizam. Segundo Morais (1996) e Capovilla e Capovilla (2004), a questão das dificuldades de aprendizagem é abordada somente pelos estudiosos do método fônico, que asseguram que os princípios dessa metodologia de ensino favorecem àqueles alunos com dificuldades, devido à ênfase dada à consciência fonológica, ao estudo das unidades mínimas das palavras - fonema / grafema, e à aprendizagem da leitura de forma progressiva (letra, sílaba, palavra, frase e, por fim, texto).

Entretanto, ao lado desses argumentos positivos, vêm as críticas que consideram o método fônico mecanicista e repetitivo, desprovido de motivação, ao passo que o método global seria omissivo em relação à consciência fonológica, à relação grafema - fonema, ao princípio alfabético, elementos indissociáveis à alfabetização eficaz. 


\section{Considerações finais: a combinação possível}

Então, qual é a saída para um ensino de qualidade? Que contribuições os métodos fônico e global podem oferecer para a alfabetização de crianças? Qual é a proposta que proporciona maior sucesso? Essas são algumas questões que devem ser respondidas no intuito de descobrir a melhor forma de proporcionar às crianças o acesso real ao prazer e à aprendizagem através da leitura.

Como afirma Cagliari (1996) e Ferreiro e Teberosky (1985), nenhum método garante bons resultados sempre e em qualquer lugar. O método pode facilitar ou dificultar, mas não criar aprendizagens, isso só se obtém com bom senso, dedicação e competência do professor em conjunto com o esforço e a motivação para aprender do aluno.

Conforme cita a Unesco, a alfabetização contribui para a liberdade e para a igualdade, sendo parte integrante de um projeto social que tem como objetivo uma sociedade mais justa e mais equitativa. Nenhuma sociedade pode funcionar no mundo de hoje sem a dimensão escrita da comunicação - texto sobre papel, na tela do computador, na televisão, acoplado a imagens e ícones de toda a espécie. Portanto, a alfabetização é uma etapa inevitável e desejável da vida no mundo atual.

Capovilla e Capovilla (2004, p. 36) afirmam que, conforme o relatório francês Aprender a ler, o professor alfabetizador precisa combinar, na sua sala de aula, o domínio da decodificação com o trabalho da construção do significado, isto é, combinar as características favoráveis do método fônico com as do método global. Para que isso aconteça, é necessário que a criança descubra o princípio alfabético e compreenda como funciona o código alfabético para dominar a decodificação e ser exposta a textos reais, ricos e com significado cultural, para tomar consciência da diversidade de textos na construção do significado.

Seguindo esse raciocínio, é sensata a busca pelo equilíbrio no uso dos dois métodos de alfabetização: fônico e global. Respeitar o caminho dos alunos no desenvolvimento de suas hipóteses sobre a escrita, possibilitar o trabalho com textos, resgatar o trabalho com o alfabeto, explorando as relações entre sons e letras e a consciência 
fonológica, respeitar os momentos de descoberta dos alfabetizandos, focalizando sempre o objeto da aprendizagem da leitura e da escrita, associar leitura e escrita a seus aspectos lúdicos e funcionais parecem ser atividades desejáveis e compatíveis. Portanto, após todas essas considerações, parece-nos que o método mais adequado para a alfabetização de crianças é aquele que compatibilize diferentes estratégias de aquisição e construção do conhecimento. Como afirmam Rayner e colaboradores (2001, 2002), a combinação de métodos baseados na significação (palavra, contexto) e nos aspectos fônicos (relação grafema - fonema) é mais poderosa do que qualquer método usado sozinho.

\section{Referências}

ADAMS, M. J.; BEARD, R.; CAPOVILLA, F.; CARDOSOMARTINS, C.; GOMBERG, J. E.; MORAS, J.; ARAÚJO E OLIVEIRA, J. B. Relatório Final de Grupo de Trabalho Alfabetização Infantil: os novos caminhos. Brasilia, DF: Congresso Nacional, 2003. Disponível em: <http:/www2.camara.gov.br/ comissões/cec/relatórios/Relat_Final.pdf $>$ Acesso em: 28 abr. 2007.

BATISTA, A. A. G.; SILVA, C. S. R.; SILVA FRADE, I. C. A.; BREGUNCI, M.G.; COSTA VAL, M. G. F.; CASTANHEIRA, M. L.; MONTEIRO, S. M. Pró-Letramento - Programa de Formação Continuada de Professores dos Anos/Séries Iniciais do Ensino Fundamental: Alfabetização e Linguagem. Brasília: Ministério da Educação; Secretaria de Educação Básica, 2007.

CAGLIARI, L. C. Alfabetização e Lingüística. 9. ed. São Paulo: Scipione, 1996.

CAPOVILLA, A. G. S.; CAPOVILLA, F. C. Alfabetização: método fônico. São Paulo: Memnon, 2004.

FERREIRO, E. Desenvolvimento da alfabetização: psicogênese. In: GOODMAN, Y. M. (Org.). Como as crianças constroem a leitura e a escrita: perspectivas piagetianas. Porto Alegre: Artes Médicas, 1995. 
FERREIRO, E.; TEBEROSKI, A. Psicogênese da Leitura e da Escrita. Porto Alegre: Artes Médicas, 1985.

GROSSI, E. P. Alfabetização e novas bases. Porto Alegre: Kuarup, 1989.

Aplicação dos princípios da psicogênese à alfabetização de crianças brasileiras de classes populares. IN: GOODMAN, Y. M. (Org.). Como as crianças constroem a leitura e a escrita: perspectivas piagetianas. Porto Alegre: Artes Médicas, 1995.

INEP - INSTITUTO NACIONAL DE ESTUDOS E PESQUISAS EDUCACIONAIS. Relatório Saeb 2005. Brasília, DF: Inep-Mec. Disponível em: <http//www.inep.gov.br>. Acesso em: 20 abr. 2007.

Pisa 2006. Brasília, DF: Inep-Mec. Disponível em: <http:// www.inep.gov.br/download/internacional/pisa/PISA2006Resultados_internacionais_resumo.pdf>. Acesso em: 2 abr. 2008.

KATO, M. A. O aprendizado da leitura. 4. ed. São Paulo: Martins Fontes, 1995.

KLEIMAN, A. Texto e leitor: aspectos cognitivos da leitura. Campinas: Pontes, 2002.

MARCUSCHI, L. A.; XAVIER, A. C. (Orgs). Hipertexto e gêneros digitais: novas formas de construção de sentido. 2. ed. Rio de Janeiro: Lucerna, 2005.

MC GUINNESS, D. O ensino da leitura. Porto Alegre: Artes Médicas, 2006.

MORAIS, J. A arte de ler. São Paulo: UNESP, 1996.

MORAIS, J.; KOLINSKY, R.; GRIMM-CABRAL, L. A aprendizagem da leitura segundo a psicolingüística cognitiva. In: RODRIGUES, C.; TOMITCH, L. M. B. (Org.). Linguagem e cérebro humano: contribuições multidisciplinares. Porto Alegre: Artmed, 2004. 
RAYNER, K.; FOORMAN, B. R.; PERFETTI, C. A.; PESETSKY, D.; SEIDENBERG, M.S. How psychological science informs the teaching of reading. Psychological Science in the public interest, v. 2, n. 2, 2001.

RAYNER, K.; FOORMAN, B. R.; PERFETTI, C. A.; PESETSKY, D.; SEIDENBERG, M.S. How should reading be taught? Scientific American, n. 286, p. 84-91, 2002.

SCLIAR-CABRAL, L. Guia prático de alfabetização. São Paulo: Contexto, 2003.

SOARES, M. Letramento: um tema em três gêneros. Belo Horizonte: Autêntica, 2000.

. Novas práticas de leitura e escrita: letramento na cibercultura. Educ. Soc., Campinas, v. 23, n. 81, p. 143-160, dez. 2002.

. A reinvenção da alfabetização. Presença Pedagógica, v. 9, n. 52, p. 15-21, 2003. Disponível em: <http://www.meb.org.br/ biblioteca/artigomagdasoares $>$. Acesso em: 1 maio 2007.

2007.

Alfabetização e Letramento. 5. ed. São Paulo: Contexto, 